\title{
A transient model of vanadium redox flow battery
}

\author{
Hassan Ali Ozgoli ${ }^{1, a}$ and Saeed Elyasi ${ }^{2}$ \\ 1 Department of Mechanical Engineering, Iranian Research Organization for Science and Technology (IROST), \\ P.O. Box 33535111, Tehran, Iran \\ 2 Chemical Engineering Department, Sharif University of Technology, Tehran, Iran
}

Received 11 Septembre 2014, Accepted 1 Octobre 2015

\begin{abstract}
It has been attempted to gain a new viewpoint in transient cell modeling of vanadium redox flow battery. This has been achieved by considering electrochemical relations along with conceptual electrical circuit of this kind of battery. The redox flow battery is one of the best rechargeable batteries because of its capability to average loads and output power sources. A model of transient behavior is presented in this paper. The transient features are considered as the most remarkable characteristics of the battery. The chemical reactions, fluid flow, and electrical circuit of the structure govern the dynamics. The transient behavior of the redox flow battery based on chemical reactions is discussed in this paper. According to the model responses, the relation between electrolyte concentration changes and the battery cell with current density has been studied in transient state and the rate of state of charge changes has been achieved. Sensitivity analysis based on the presented model indicated that the battery voltage highly depends on the concentration amount of reactants. In addition the negative effect of the operation temperature increases on one hand and the effect of electrolyte fluid flow rate on the other hand have been noticed on output voltage of the cell.
\end{abstract}

Key words: Vanadium redox flow battery / transient model / concentration / porous electrode / electrolyte solution

\section{Introduction}

Energy storage technologies will bear much more extensive functions to be utilized in efficient energy producing systems, in near future.

The redox flow battery is one of the most exclusive technologies in energy storage field to be used in energy recyclable generations such as peak shaving and electric load leveling. In this regard attaching VRB with wind and solar photovoltaic power plants can increase the grid security in addition to stability of electrical output [1-3].

The production rate of these power plants varies due to climate, season and other environmental factors [4]. Power production by photovoltaic and wind generator along with VRB energy storage system is a novel approach. Choosing this method decreases the load of grid transmission and power distribution. In this case these systems can be substituted to conventional power generation systems $[5,6]$.

One of the most critical technologies in VRB is that vanadium battery power depends on the whole electrolyte fluid on the electrodes of the stacks. It means that it is

\footnotetext{
a Corresponding author: a.ozgoli@irost.ir
}

possible to increase the amount of stored energy by just increasing the volume capacity of the charged electrolyte without changing the dimensions of the stack [7-9].

In addition the stacks are not necessary to be discharged by the same voltage they have been charged. There is also the possibility of discharging one stack whilst the other is being charged [10-12].

Vanadium redox flow batteries have received much attention in recent years for large energy storage in micro grids. VRBs are well known and because they are designing flexibly, manufactured in low cost for large scale, and their electrolytes have indefinite lifetime and are recyclable. VRB modeling is the perquisite for battery analysis $[13,14]$.

Different aspects of issue to be considered in cell design have been mentioned in Esfahanian et al. [15].

Study such as key materials and electrode and membrane is investigated. The defined mathematical framework in previous study [16] was utilized to develop formulation for steady state model by You et al. [17]. Determination of the effect of current density and SOC has been done in this study.

Transient modeling along with experimental tests of a VRB was done by Shah et al. [16] and the fluid flow rate 


\section{Nomenclature}

\begin{tabular}{|c|c|c|c|}
\hline$a$ & Specific surface area $\left[\mathrm{m}^{2} \cdot \mathrm{m}^{-3}\right]$ & VRB & Vanadium Redox flow Battery \\
\hline$A$ & Specific area $\left[\mathrm{m}^{2} \cdot \mathrm{m}^{-3}\right]$ & $X$ & Identity matrix \\
\hline aq & Aqua & $z$ & Charge of the ionic species, dimensionless \\
\hline \multirow{2}{*}{$\begin{array}{l}c \\
C F D\end{array}$} & Concentration $\left[\mathrm{mol} . \mathrm{m}^{-3}\right]$ & $Z$ & Impedance of battery $(\Omega)$ \\
\hline & Computational Fluid Dynamics & \multicolumn{2}{|r|}{ Greek } \\
\hline$d$ & Electrode thickness $[\mathrm{m}]$ & $\alpha$ & Transfer coefficient, dimensionless \\
\hline$d_{\mathrm{f}}$ & Carbon electrode fiber diameter $[\mathrm{m}]$ & $\beta$ & Permeability coefficient \\
\hline$D$ & Diffusion coefficient $\left[\mathrm{m}^{2} \cdot \mathrm{s}^{-1}\right]$ & $\varepsilon$ & Porosity, dimensionless \\
\hline$E$ & Nernst or equilibrium potential [V] & $\eta$ & Over-potential [V] \\
\hline$E_{\text {no }}$ & No-load voltage $[\mathrm{V}]$ & $\phi_{s}$ & Electronic potential $[\mathrm{V}]$ \\
\hline$E_{\text {on }}$ & On-load voltage $[\mathrm{V}]$ & $\phi_{l}$ & Ionic potential $[\mathrm{V}]$ \\
\hline$f$ & External body forces acting on the fluid & $\kappa$ & Permeability $\left[\mathrm{m}^{2}\right]$ \\
\hline$F$ & Faraday's constant $\left[\mathrm{C} \cdot \mathrm{mol}^{-1}\right]$ & $\sigma$ & Electronic conductivity $\left[{\left.\mathrm{S} . \mathrm{m}^{-1}\right]}^{-1}\right.$ \\
\hline$H$ & Cell height $[\mathrm{m}]$ & $\kappa_{l_{m}}^{\mathrm{eff}}$ & Conductivity of membrane $\left[\mathrm{S}^{-\mathrm{m}^{-1}}\right]$ \\
\hline$\vec{i}$ & Current density $\left[\right.$ A.m $\left.{ }^{-2}\right]$ & $\mu$ & Dynamic viscosity [Pa.s] \\
\hline$i^{0}$ & Exchange current density $\left[\mathrm{A} \cdot \mathrm{m}^{-2}\right]$ & $\delta$ & Characteristic pore size $[\mathrm{m}]$ \\
\hline$I$ & Charge/discharge current $[\mathrm{A}]$ & $\rho$ & Constant density $\left[\mathrm{kg} \cdot \mathrm{m}^{-3}\right]$ \\
\hline$I_{\mathrm{app}}$ & Applied current density $\left[\right.$ A.m $\left.{ }^{-2}\right]$ & \multicolumn{2}{|r|}{ Subscript and Superscrip } \\
\hline$j$ & Faradic interfacial current density $\left[{\left.\mathrm{A} . \mathrm{m}^{-2}\right]}^{-2}\right.$ & $\mathrm{a}$ & Anodic reaction quantity \\
\hline$k$ & Reaction rate constant $\left[\mathrm{m} \cdot \mathrm{s}^{-1}\right]$ & $\mathrm{c}$ & Cathodic reaction quantity \\
\hline$k_{\mathrm{CK}}$ & Kozeny-Carman constant, dimensionless & cell & Cell \\
\hline$k_{\mathrm{m}}$ & Local mass transfer coefficient $\left[\mathrm{m} . \mathrm{s}^{-1}\right]$ & $\mathrm{e}$ & Electrode \\
\hline$L$ & Inductor & eff & Effective value \\
\hline$n_{\mathrm{A}}$ & Avogadro's number $\left[6.02 \times 10^{23} \mathrm{~mol}^{-1}\right]$ & $\mathrm{f}$ & Fixed charge quantity \\
\hline$n_{\mathrm{V}}$ & Number of equivalents per mole of vanadium & $\mathrm{H}^{+}$ & Proton property \\
\hline$N$ & Number of $\mathrm{V}^{2+}$ & $i$ & Species $i \in\left\{\mathrm{V}^{2+}, \mathrm{V}^{3+}, \mathrm{VO}^{2+}, \mathrm{VO}_{2}^{+}, \mathrm{H}^{+}\right\}$ \\
\hline$\vec{n}$ & Outward normal vector & in & Inlet value \\
\hline$\vec{N}$ & Flux $\left[\right.$ mol.m $\left.{ }^{-2} \cdot \mathrm{s}^{-1}\right]$ & 1 & Electrolyte quantity \\
\hline$O C V$ & Open Circuit Voltage [V] & $\mathrm{m}$ & Membrane quantity/property \\
\hline$P$ & Liquid pressure $[\mathrm{Pa}]$ & neg & Negative electrode quantity/property \\
\hline$Q$ & Volumetric flow rate $\left[\mathrm{mL} \cdot \mathrm{min}^{-1}\right]$ & out & Outlet value \\
\hline$r$ & Darcy's law resistance matrix & pos & Positive electrode quantity/property \\
\hline$R$ & Universal gas constant $\left[\mathrm{J} \cdot \mathrm{mol}^{-1} \cdot \mathrm{K}^{-1}\right]$ & $\mathrm{s}$ & Solid or electronic property \\
\hline $\mathrm{SOC}$ & State Of Charge & & \\
\hline$S$ & Source term $\left[\mathrm{mol} \cdot \mathrm{m}^{-3} \cdot \mathrm{s}^{-1}\right]$ & $\operatorname{tank}$ & Tank \\
\hline$T$ & Temperature $[\mathrm{K}]$ & $x$ & Component in the $x$ direction \\
\hline$u$ & Velocity vector $\left[\mathrm{m} . \mathrm{s}^{-1}\right]$ & $y$ & Component in the $y$ direction \\
\hline$\vec{v}$ & Velocity of the electrolyte flow $\left[\mathrm{m}_{\mathrm{s}} \mathrm{s}^{-1}\right]$ & & \\
\hline$V$ & Volume $[\mathrm{L}]$ & & \\
\hline
\end{tabular}

in inlets, concentration and also electrode porosity were noticed on efficiency.

In another research Tang, Skyllas-Kazacos et al. [18] indicated that the temperature of the electrolyte solution can also be effective in changing the VRB output. The results of this study indicated that increase in current density or decrease in flow rate can change the temperature of the stack and electrolyte. Measuring and monitoring the amount of SOC in battery operating time can result in supervision on the capacity of electrical potential production of the battery.

Different methods to designated SOC to be used in VRBs have been studied by Corcuera and SkyllasKazacos [19]. According to carried out studies; the achieved amount for each half-cell bears a slight discrepancy in comparison with the experimental model.

In order to achieve a more accurate method for VRB battery loss Knehr et al. [20] have constructed an isothermal transient model. In this model, ion transmission through cell membrane which is occurred due to convection, diffusion and migration has been considered.

A mathematical model has been presented to predict the process of a kilo Watt-class type VRB stack self-discharge by You et al. [21]. The mathematical and experimental results indicated that the diffusion rate of vanadium ions depends on diffusion coefficient, partition coefficient and the gradient of vanadium ion concentration between two half-cells. The results of mathematical and experimental models have indicated the time duration of changes in vanadium ion concentration between two half-cells by the time of $\mathrm{V}^{2+}$ and $\mathrm{VO}^{2+}$ ions to be extinct.

Li and Hikihara [22] have observed the behavior of a battery in transient state. Change in reactant concentration has been calculated by a differential model and has been adjusted with the experimental results. This 


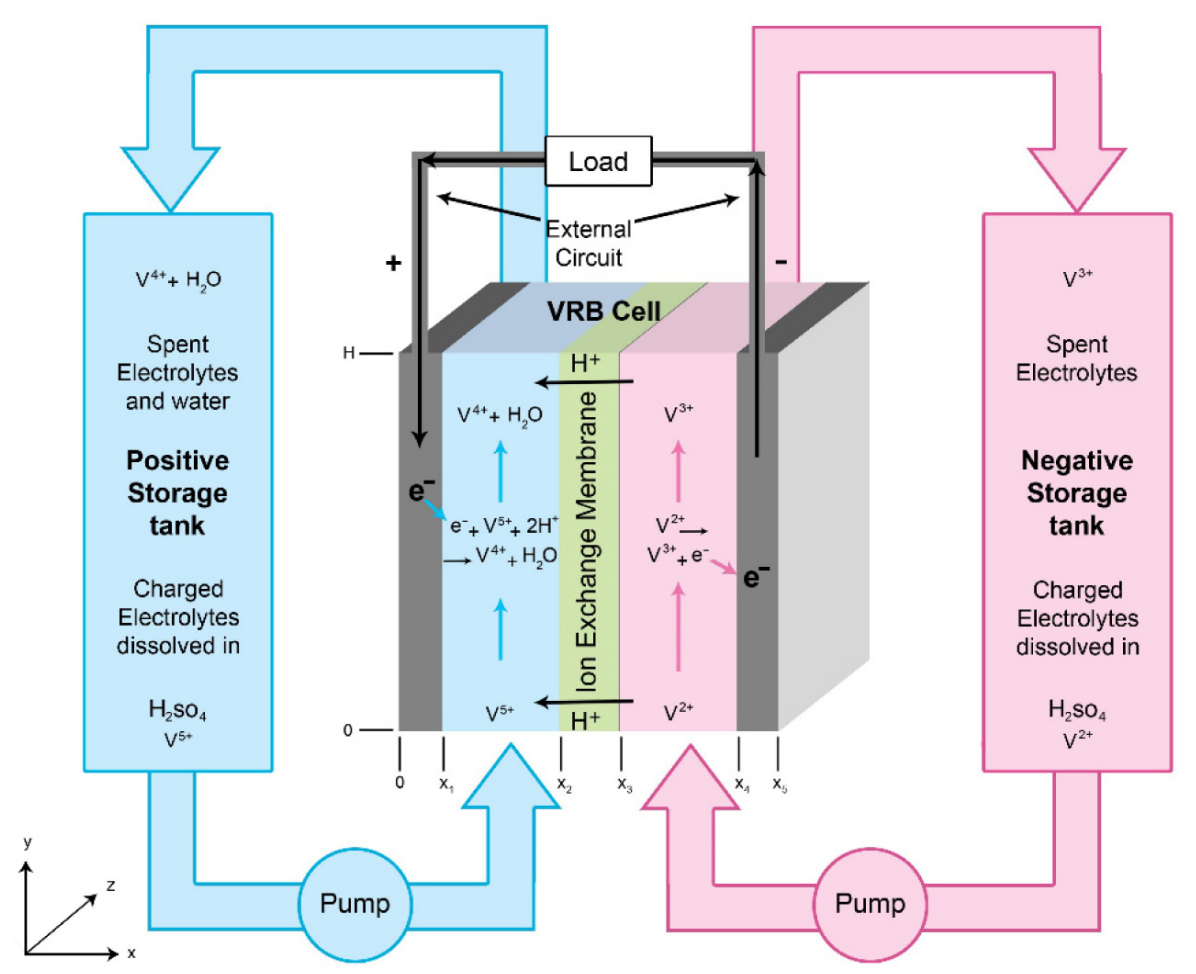

Fig. 1. Schematic of VRB operation.

reactant concentration leads to changes in electrochemical potential of the battery in charge and discharge states. The model indicated that chemical reaction rate is limited by attaching an external electrical circuit to the battery and also the fluid flow.

Studies have been carried out on a VRB sample with $10 \mathrm{~kW}$ capacity by Zhoa et al. [23]. Voltage changes of $1 \mathrm{~kW}$ stacks, the combination of attached stacks and also changes in charge and discharge time output have been calculated. The output result indicated more than $80 \%$ efficiency for the battery stack.

A model based on an equivalent circuit researched by Mohamed et al. [24] has been presented. This model has been constructed according to VRB experimental equilibrium and ohmic resistance data gathering. This used to demonstrate the polarization features of the battery by means of extended Kalman filter. The model demonstrates to be consistent over different pulse-relaxation tests at different SOC of the VRB.

A thermal dependent electrical circuit has been suggested to describe the VRB charge and discharge characteristics in a study done by Binyu et al. [25]. The model has been approved by experimental data. SOC evaluation is one of the most crucial in VRB management. Since a correct evaluation can prevent the battery from overcharge and discharge. Extended Kalman filter has been carried out in this model to gain a solid SOC analysis. The simulation results indicate that the mentioned simulator has considered exact according to temperature changes.

A lumped model has determined the effect of the pump in temperature increase and has analyzed VRB responses in different VRB environmental temperatures [26]. Electrolyte flow velocity and temperature effects on battery electrical features and output have also been considered. $1 \mathrm{~kW}$ VRB system has been selected to carry out numerical simulations. Thermal models have been validated with experimental data and a good agreement has been noticed. Also the results of simulation indicate that the power of the pump is sensitive to hydraulic design and flow rate.

Numerical modeling and simulation of a vanadium redox flow battery have been provided in this study. As a novelty, a model based on electrochemical reactions along with equivalent electrical circuit has been developed here. The effects of concentration changes, electrolyte flow rate, and operation temperature on the output voltage and SOC during battery operation are investigated by means of this model. Also, the flow rate, temperature and electrolyte concentration that is more suitable for VRB are identified.

\section{Model development}

\subsection{Model assumptions}

Two reactions take place in two sides of the membrane simultaneously while discharging; the electrons separate the anolyte and enter the catholyte side. According to Figure 1 while charging the electron's direction reverses. Reduction occurs in anolyte side and as oxidation occurs in catholyte side. VRBs development is based on vanadium capability in four different oxide states. 
$\mathrm{V}^{4+}$ and $\mathrm{V}^{5+}$ are in fact oxide vanadium of $\mathrm{VO}^{2+}$ and $\mathrm{VO}_{2}^{+}$. Therefore, the equations of $\mathrm{VRB}$ reactions are calculated as follow $[27]$ :

$$
\begin{aligned}
& \mathrm{VO}_{2}^{+}+2 \mathrm{H}^{+}+\mathrm{e}^{-} \leftrightarrow \mathrm{VO}^{2+}+\mathrm{H}_{2} \mathrm{O} \\
& \frac{\mathrm{V}^{2+} \leftrightarrow \mathrm{V}^{3+}+\mathrm{e}^{-}}{\mathrm{V}^{2+}+\mathrm{VO}^{2+}+2 \mathrm{H}^{+} \leftrightarrow \mathrm{VO}^{2+}+\mathrm{V}^{3+}+\mathrm{H}_{2} \mathrm{O}}
\end{aligned}
$$

1. The fluid flow has been considered incompressible. It has been assumed that the fluid density remains unchanged during operation. This assumption in truly approved.

2. Electrolyte physical features, electrolyte and the membrane have been considered isentropic and homogenous and their changes have been neglected in different aspects.

3. The isothermal condition has been considered for all the parts. The effect of temperature changes in the process has been studied in sensitivity analysis of the present paper.

4. Side reactions such as oxygen and hydrogen changes have not been studied.

5. The gravity effects have been neglected.

6 . The effects of water penetration through the membrane have been neglected. It has been assumed that the membrane just let the protons' entrance and water can not be penetrated.

7. The model has been considered in a transient way.

8. The electrode material has been made of carbon.

9. The membrane material has been made of Nafion [17,27].

\subsection{Governing equations}

The following equations presented the conservation $[16]$ :

Continuity: $\nabla \cdot \vec{v}=0$

Momentum conservation: $\frac{\mu}{K} \vec{v}=-\nabla P$

Species conservation: $\vec{v} \nabla c_{i}-D_{i}^{\mathrm{eff}} \nabla^{2} c_{i}=S_{i}$

Charge conservation: $\nabla \cdot \vec{i}_{s}=-\nabla \cdot \vec{i}_{l}=-\sigma_{s}^{\text {eff }} \nabla^{2} \phi_{s}=$ $-K_{l}^{\mathrm{eff}} \nabla^{2} \phi_{l}=S_{\phi}$

$\vec{v}$ refers to the intrinsic fluid velocity vector; $P$, refers to the fluid pressure; $c_{i}$, refers to the concentration of species $i, i \in\left\{\mathrm{V}^{2+}, \mathrm{V}^{3+}, \mathrm{VO}^{2+}, \mathrm{VO}^{2+}, \mathrm{H}^{+}\right\} ; S_{i}$, denotes the source term for species $i ; \phi_{s}$ and $\phi_{l}$ denote the potential of the solid and liquid phase, respectively; $S_{\phi}$, denotes the source term for charge conservation.

Table 1 lists the source terms for species conservation and charge conservation in the positive and negative electrodes. The source terms in the membrane are all set to zero. It is crucial because the conversation equations can't be solved without coupling the Butler-Volmer law $[17,28,29]$.

$$
\begin{aligned}
j_{\mathrm{pos}}= & i_{0, \mathrm{pos}}\left[\frac{c_{5}^{s}}{c_{5}} \exp \left(\frac{\left(-\alpha_{\mathrm{pos}, \mathrm{c}}\right) \mathrm{F} \eta_{\mathrm{pos}}}{\mathrm{RT}}\right)\right. \\
& \left.-\frac{c_{4}^{s}}{c_{4}} \exp \left(\frac{\alpha_{\mathrm{pos}, \mathrm{a}} \mathrm{F} \eta_{\mathrm{pos}}}{\mathrm{RT}}\right)\right] \\
j_{\text {neg }}= & i_{0, \text { neg }}\left[\frac{c_{3}^{s}}{c_{3}} \exp \left(\frac{\left(-\alpha_{\text {neg, } \mathrm{c}}\right) \mathrm{F} \eta_{\mathrm{neg}}}{\mathrm{RT}}\right)\right. \\
& \left.-\frac{c_{2}^{s}}{c_{2}} \exp \left(\frac{\alpha_{\text {neg, }} \mathrm{F} \eta_{\mathrm{neg}}}{\mathrm{RT}}\right)\right]
\end{aligned}
$$

$j_{\text {pos }}$ and $j_{\text {neg }}$ are considered as the transfer current densities for the positive and negative electrodes respectively. The exchange current densities for the positive and negative electrode reactions are as follow $[16,20]$ :

$$
\begin{aligned}
& i_{\text {pos }}^{0}=F k_{\text {pos }}\left(c_{4}\right)^{\alpha_{\text {pos }, \mathrm{c}}}\left(c_{5}\right)^{\alpha_{\text {pos }, \mathrm{a}}} \\
& i_{\text {neg }}^{0}=F k_{\text {neg }}\left(c_{2}\right)^{\alpha_{\text {neg }, \mathrm{c}}}\left(c_{3}\right)^{\alpha_{\text {neg }, \mathrm{a}}}
\end{aligned}
$$

The over-potentials for the positive and negative electrode reactions are defined as:

$$
\begin{aligned}
& \eta_{\mathrm{pos}}=\phi_{s}-\phi_{l}-E_{\mathrm{pos}} \\
& \eta_{\mathrm{neg}}=\phi_{s}-\phi_{l}-E_{\mathrm{neg}}
\end{aligned}
$$

where $E_{\mathrm{pos}}$ and $E_{\text {neg }}$ can be estimated from the relevant Nernst equations [20]:

$$
\begin{aligned}
& E_{\mathrm{pos}}=E_{\mathrm{pos}}^{0}+\frac{R T}{F} \operatorname{Ln}\left(\frac{c_{5}}{c_{4}}\right) \\
& E_{\mathrm{neg}}=E_{\mathrm{neg}}^{0}+\frac{R T}{F} \operatorname{Ln}\left(\frac{c_{3}}{c_{2}}\right)
\end{aligned}
$$

The values of the equilibrium potentials $E_{\text {pos }}^{0}$ and $E_{\text {neg }}^{0}$ have been categorized in Table 2 .

Introducing the local mass transfer coefficient $k_{m}$ to describe the effect of species transport between the bulk solution and the liquid-solid interface, thus the local flux at the surface of the positive electrode during charge will be defined as $[20,30]$ :

$$
\begin{array}{r}
N_{4}^{s}=k_{\mathrm{m}, \mathrm{pos}}\left(c_{4}-c_{4}^{s}\right)=k_{\mathrm{pos}}\left(c_{4}\right)^{\alpha_{\mathrm{pos}, \mathrm{c}}}\left(c_{5}\right)^{\alpha_{\mathrm{pos}, \mathrm{a}}} \\
\times\left[\frac{c_{4}^{s}}{c_{4}} \exp \left(\frac{\left(\alpha_{\mathrm{pos}, \mathrm{a}}\right) F \eta_{\mathrm{pos}}}{R T}\right)-\frac{c_{5}^{s}}{c_{5}} \exp \left(-\frac{\alpha_{\mathrm{pos}, \mathrm{c}} F \eta_{\mathrm{pos}}}{R T}\right)\right]
\end{array}
$$

$$
\begin{array}{r}
N_{5}^{s}=k_{\mathrm{m}, \mathrm{pos}}\left(c_{5}-c_{5}^{s}\right)=k_{\mathrm{pos}}\left(c_{5}\right)^{\alpha_{\mathrm{pos}, \mathrm{c}}}\left(c_{5}\right)^{\alpha_{\mathrm{pos}, \mathrm{a}}} \\
\times\left[\frac{c_{5}^{s}}{c_{5}} \exp \left(-\frac{\left(\alpha_{\mathrm{pos}, \mathrm{c}}\right) F \eta_{\mathrm{pos}}}{R T}\right)-\frac{c_{4}^{s}}{c_{4}} \exp \left(\frac{\alpha_{\mathrm{pos}, \mathrm{a}} F \eta_{\mathrm{pos}}}{R T}\right)\right]
\end{array}
$$

Combining Equations (14) and (15), the vanadium concentrations at the surface of the positive electrode will be $[16,17]$ :

$$
\begin{aligned}
c_{4}^{s} & =\frac{B_{\mathrm{pos}} c_{5}+\left(1+B_{\mathrm{pos}}\right) c_{4}}{1+A_{\mathrm{pos}}+B_{\mathrm{pos}}} \\
c_{5}^{s} & =\frac{A_{\mathrm{pos}} c_{4}+\left(1+A_{\mathrm{pos}}\right) c_{5}}{1+A_{\mathrm{pos}}+B_{\mathrm{pos}}}
\end{aligned}
$$


H.A. Ozgoli and S. Elyasi: Mechanics \& Industry 17, 406 (2016)

Table 1. Source terms for species and charge conservation.

\begin{tabular}{ccccc}
\hline Source term & \multicolumn{2}{c}{ Positive electrode } & \multicolumn{2}{c}{ Negative electrode } \\
\hline \multirow{2}{*}{$\mathrm{S}_{1}$} & $\mathrm{VO}^{2+}$ & $a \mathrm{j}_{\text {pos }} / \mathrm{F}$ & $\mathrm{V}^{2+}$ & $a \mathrm{j}_{\text {neg }} / \mathrm{F}$ \\
& $\mathrm{VO}_{2}^{+}$ & $-a \mathrm{j}_{\text {pos }} / \mathrm{F}$ & $\mathrm{V}^{3+}$ & $-a \mathrm{j}_{\text {neg }} / \mathrm{F}$ \\
& $\mathrm{H}^{+}$ & $-2 \times a \mathrm{j}_{\text {pos }} / \mathrm{F}$ & $\mathrm{H}^{+}$ & \\
\hline \multirow{2}{*}{$\mathrm{S}_{\phi}$} & $\phi_{\mathrm{s}}$ & $a \mathrm{j}_{\text {pos }}$ & $\phi_{\mathrm{s}}$ & $a \mathrm{j}_{\text {neg }}$ \\
& $\phi_{\mathrm{l}}$ & $-a \mathrm{j}_{\mathrm{pos}}$ & $\phi_{1}$ & $-a \mathrm{j}_{\mathrm{n} \text { eg }}$ \\
\hline
\end{tabular}

Table 2. Considered kinetic parameters in VRB modeling.

\begin{tabular}{cccc}
\hline Parameter & Value & Unit & Description \\
\hline$k_{\text {pos }}$ & $2.50 \times 10^{-8}$ & $\mathrm{~m} . \mathrm{s}^{-1}$ & Rate constant, positive reaction \\
$k_{\text {neg }}$ & $7.00 \times 10^{-8}$ & $\mathrm{~m} . \mathrm{s}^{-1}$ & Rate constant, negative reaction \\
$\alpha_{\text {pos }, \mathrm{a}}$ & 0.55 & - & Anodic transfer coefficient, positive reaction \\
$\alpha_{\text {pos,c }}$ & 0.55 & - & Cathodic transfer coefficient, positive reaction \\
$\alpha_{\text {neg, }}$ & 0.45 & - & Anodic transfer coefficient, negative reaction \\
$\alpha_{\text {neg,c }}$ & 0.45 & - & Cathodic transfer coefficient, negative reaction \\
$E_{\text {pos }}^{0}$ & 1.004 & $\mathrm{~V}$ & Standard potential, positive reaction \\
$E_{\text {neg }}^{0}$ & -0.255 & $\mathrm{~V}$ & Standard potential, negative reaction \\
\hline
\end{tabular}

where $A_{\text {pos }}$ and $B_{\text {pos }}$ have the following expressions [17, 21,31]:

$$
A_{\mathrm{pos}}=\frac{k_{\mathrm{pos}}}{k_{\mathrm{m}, \mathrm{pos}}}\left(c_{4}\right)^{\alpha_{\mathrm{pos}, \mathrm{c}}-1}\left(c_{5}\right)^{\alpha_{\mathrm{pos}, \mathrm{a}}} \exp \left(\frac{\alpha_{\mathrm{pos}, \mathrm{a}} F \eta_{\mathrm{pos}}}{R T}\right)
$$

$B_{\mathrm{pos}}=\frac{k_{\mathrm{pos}}}{k_{\mathrm{m}, \mathrm{pos}}}\left(c_{4}\right)^{\alpha_{\mathrm{pos}, \mathrm{c}}}\left(c_{5}\right)^{\alpha_{\mathrm{pos}, \mathrm{a}}-1} \exp \left(-\frac{\alpha_{\mathrm{pos}, \mathrm{c}} F \eta_{\mathrm{pos}}}{R T}\right)$

The mass transfer coefficient can be approximately calculated by [32]:

$$
k_{\mathrm{m}, \mathrm{pos}}=1.6 \times 10^{-4}|\vec{v}|^{0.4}
$$

Similar expressions are applied to the species at the negative electrode as follows:

$$
\begin{gathered}
c_{2}^{s}=\frac{B_{\text {neg }} c_{3}+\left(1+B_{\text {neg }}\right) c_{2}}{1+A_{\text {neg }}+B_{\text {neg }}} \\
c_{3}^{s}=\frac{A_{\text {neg }} c_{2}+\left(1+A_{\text {neg }}\right) c_{3}}{1+A_{\text {neg }}+B_{\text {neg }}}
\end{gathered}
$$

where

$$
\begin{aligned}
& A_{\text {neg }}=\frac{k_{\text {neg }}}{k_{m, \text { neg }}}\left(c_{2}\right)^{\alpha_{\text {neg }, \mathrm{c}}-1}\left(c_{3}\right)^{\alpha_{\text {neg, a }}} \exp \left(\frac{\alpha_{\text {neg }, \mathrm{a}} F \eta_{\text {neg }}}{R T}\right) \\
& B_{\text {neg }}=\frac{k_{\text {neg }}}{k_{m, \text { neg }}}\left(c_{2}\right)^{\alpha_{\text {neg }, \mathrm{c}}}\left(c_{3}\right)^{\alpha_{\text {neg }, \mathrm{a}}-1} \exp \left(\frac{\alpha_{\text {neg,c }} F \eta_{\text {neg }}}{R T}\right)
\end{aligned}
$$

The local mass transfer coefficient $k_{\mathrm{m}, \mathrm{neg}}$ has the same expression as Equation (20).

The permeability of the porous media is often described by the Carman-Kozeny equation [33]:

$$
\kappa=\frac{d_{f}^{2} \varepsilon^{3}}{16 k_{\mathrm{CK}}(1-\varepsilon)^{2}}
$$

where $k_{\mathrm{CK}}$ is the Carman-Kozeny constant, which depends on the type of media and is used as a fitting parameter and $d_{f}$ is the fiber diameter, $\varepsilon$ is the porosity, the value of the specific surface area relates to $\varepsilon$ according to the calculation of the specific area in reference [34]. Equation below shows the correction of specific surface area " $a$ " in Table 1:

$$
a=\left(\frac{\varepsilon}{\varepsilon_{0}}\right)^{0.75} A_{e}
$$

Values of porosity and specific surface area are shown in Table 3 where $\varepsilon_{0}$ and $A_{e}$ are the reference. The effective diffusion coefficient $D_{i}^{\text {eff }}$ and the effective conductivity of the porous carbon electrode are calculated by the Bruggemann correction [16].

$$
\begin{aligned}
D_{i}^{\text {eff }} & =\varepsilon^{3 / 2} D_{i} \\
\sigma_{s}^{\text {eff }} & =(1-\varepsilon)^{3 / 2} \sigma_{s}
\end{aligned}
$$

This equation shows the effective conductivity of the electrolyte [17]:

$$
\kappa_{l}^{\mathrm{eff}}=\frac{F^{2}}{R T} \sum_{i} z_{i}^{2} D_{i}^{\mathrm{eff}} c_{i}
$$

The following equation shows the effective conductivity in the membrane which has a special expression. Reference [16] indicates the detail of the deducing process.

$$
\kappa_{l_{-} m}^{\mathrm{eff}}=-\frac{F^{2}}{R T} z_{f} c_{f} D_{\mathrm{H}^{+}}^{m}
$$

where $z_{f}$ is the fixed site charge in the membrane and $c_{f}$ is the fixed charge site concentration.

\subsection{Boundary conditions}

Boundary conditions are required at all boundaries of the computational domains, as well as at internal interfaces. 
H.A. Ozgoli and S. Elyasi: Mechanics \& Industry 17, 406 (2016)

Table 3. Considered electrode properties in VRB.

\begin{tabular}{cccc}
\hline Parameter & Value & Unit & Description \\
\hline$\varepsilon_{0}$ & 0.93 & - & Electrode porosity \\
$A_{\mathrm{e}}$ & $3.50 \times 10^{+5}$ & $\mathrm{~m}^{2} \cdot \mathrm{m}^{-3}$ & Electrode specific area \\
$\sigma_{\mathrm{e}}$ & 66.7 & $\mathrm{~S}_{\mathrm{m}} \mathrm{m}^{-1}$ & Electrode conductivity \\
$k_{\mathrm{CK}}$ & 4.28 & - & Kozeny-Carman constant \\
$H$ & 0.075 & $\mathrm{~m}$ & Cell height \\
$W$ & 0.0785 & $\mathrm{~m}$ & Cell depth \\
$D$ & 0.004 & $\mathrm{~m}$ & Electrode thickness \\
\hline
\end{tabular}

\subsubsection{Boundary conditions for charge conservation}

Since the battery is operated in galvanostatic mode the flux conditions for potential distribution of the porous electrode are as follows (during charge):

$$
\begin{aligned}
& -\sigma_{s}^{\mathrm{eff}} \nabla \phi_{s} \cdot \vec{n}=I_{\text {app }}\left(x=0, x=x_{1}\right) \\
& -\sigma_{s}^{\mathrm{eff}} \nabla \phi_{s} \cdot \vec{n}=-I_{\mathrm{app}}\left(x=x_{4}\right) \\
& -\sigma_{s}^{\mathrm{eff}} \nabla \phi_{s} \cdot \vec{n}=0 \quad\left(x=x_{2}, x=x_{3}, y=0, y=H\right)
\end{aligned}
$$

The charge leaving the solid phase is balanced by the charge entering the electrolyte where $I_{\text {app }}$ is the applied current density. For discharge the signs are reversed. Therefore, the boundary conditions on the potential distribution for electrolyte during charge are specified as:

$-\kappa_{l}^{\mathrm{eff}} \nabla \phi_{l} \cdot \vec{n}=-I_{\text {app }}\left(x=x_{2}\right)$

$-\kappa_{l}^{\mathrm{eff}} \nabla \phi_{l} \cdot \vec{n}=I_{\mathrm{app}}\left(x=x_{3}\right)$

$-\kappa_{l}^{\mathrm{eff}} \nabla \phi_{l} \cdot \vec{n}=0 \quad\left(x=0, x=x_{1}, x=x_{4}, y=0, y=H\right)$

For discharge the signs are reversed.

\subsubsection{Boundary conditions for momentum balance}

Where the velocity boundary conditions are used at the inlets, pressure boundary conditions are used at the outlets and on all walls, the no-slip boundary condition is applied for the momentum equations. The detailed expressions are as follows:

$$
\begin{aligned}
v_{y} & =v_{\text {in }}(y=0) \\
P & =P_{\text {out }}(y=H) \\
\nabla P \cdot \vec{n} & =0\left(x=x_{1}, x_{2}, x_{3}, x_{4}\right)
\end{aligned}
$$

The inlet velocity can be calculated by the equation below where the outlet pressure $P_{\text {out }}$ is usually set to zero:

$$
v_{\text {in }}=\frac{Q}{\varepsilon A}
$$

The diffusive fluxes of all species are set to zero where $Q$ is the volumetric flow rate and $A$ is the cross-sectional area.
At the outlets $(y=H)[17]$ :

$$
-D_{i}^{\mathrm{eff}} \nabla c_{i} \cdot \vec{n}=0
$$

when all the other boundaries are set to walls, it means that the fluxes are zero:

$$
\left(-D_{i}^{\mathrm{eff}} \nabla c_{i}+c_{i} \vec{v}\right) \cdot \vec{n}=0
$$

\section{Concentration change}

The chemical reaction rate at charging and discharging is assumed to be the same. On the other hand, the flow rates in both electrodes are assumed to be balanced. Then, the concentration change of $\mathrm{V}^{5+}$ is given by $[16,22]$ :

$$
\begin{aligned}
\frac{\mathrm{d}\left[\mathrm{V}^{5+}\right]_{\text {cell }}}{\mathrm{d} t}=\mp k_{\text {pos }}\left[\mathrm{V}^{5+}\right]_{\text {cell }}\left[H^{+}\right]_{\text {cell }}^{2}\left[\mathrm{e}^{-}\right]_{+} \\
+\frac{Q}{\mathrm{~V}_{\text {cell }}}\left\{\left[V^{5+}\right]_{\text {tank }}-\left[V^{5+}\right]_{\text {cell }}\right\}
\end{aligned}
$$

The signs "-" and "+" imply that the concentration of cells and tanks decreases during discharge operation and increases during charging operation, respectively. The second term corresponds to the concentration change by the electrolysis circulation. The difference of concentration in tanks and cells, the flow rate of electrolysis solution, and the volume of cell govern this term. The concentration change of the vanadium ion of $\mathrm{V}^{2+}$ based in Equation (1) is given by:

$$
\begin{aligned}
\frac{\mathrm{d}\left[V^{2+}\right]_{\text {cell }}}{\mathrm{d} t}=\mp k_{\text {neg }}\left[\mathrm{V}^{2+}\right]_{\text {cell }}+\frac{Q}{\mathrm{~V}_{\text {cell }}}\{ & {\left[\mathrm{V}^{2+}\right]_{\text {tank }} } \\
& \left.-\left[\mathrm{V}^{2+}\right]_{\text {cell }}\right\}
\end{aligned}
$$

The concentration change of other ions can be modeled in the same way. Moreover, the relationship between the concentration of $\mathrm{V}^{2+}$ and the current obeys:

$$
\begin{array}{r}
\mp k_{\text {neg }}\left[\mathrm{V}^{2+}\right]_{\text {cell }}=\mp k_{\text {pos }}\left[\mathrm{V}^{5+}\right]_{\text {cell }}\left[H^{+}\right]_{\text {cell }}^{2}\left[\mathrm{e}^{-}\right]_{+} \\
=\mp \frac{I}{V_{\text {cell }} F}
\end{array}
$$

The above equation is held in charging and discharging operation [16]. The following discusses the concentration of $\mathrm{V}^{2+}$ because the concentration of $\mathrm{V}^{2+}$ is same 
as $\mathrm{V}^{5+}$. In the redox flow battery, the total number of $\mathrm{V}^{2+}$ coincides with the quantity in cells and tanks. Then, in charging and discharging operation, the following conservation relationship is held [22]:

$$
\mathrm{V}_{\text {cell }}\left[\mathrm{V}^{2+}\right]_{\text {cell }}+\mathrm{V}_{\text {tank }}\left[\mathrm{V}^{2+}\right]_{\text {tank }}=\frac{N}{n_{A}}
$$

The current $I$ in external electrical circuit governs the number of $\mathrm{V}^{2+}$ as follows [25]:

$$
\frac{1}{n_{A}} \frac{\mathrm{d} N}{\mathrm{~d} t}=\mp \frac{I}{F}
$$

The concentration change of vanadium ion $\mathrm{V}^{2+}$ is given in the cells by the following equation:

$$
\begin{aligned}
\frac{\mathrm{d}^{2}\left[\mathrm{~V}^{2+}\right]_{\text {cell }}}{\mathrm{d} t^{2}} & =-\left\{Q\left(\frac{1}{\mathrm{~V}_{\text {tank }}}+\frac{1}{\mathrm{~V}_{\text {cell }}}\right)-\frac{1}{Q} \frac{\mathrm{d} Q}{\mathrm{~d} t}\right\} \frac{\mathrm{d}\left[V^{2+}\right]_{\text {cell }}}{\mathrm{d} t} \\
& \mp \frac{1}{\mathrm{~V}_{\text {cell }} F} \frac{\mathrm{d} I}{\mathrm{~d} t} \mp\left(\frac{Q}{\mathrm{~V}_{\text {tank }}}-\frac{1}{Q} \frac{\mathrm{d} Q}{\mathrm{~d} t}\right) \frac{1}{\mathrm{~V}_{\text {cell }}} \frac{I}{F}
\end{aligned}
$$

At constant flow rate $Q_{0}$ the model Equation (48) is simplified as:

$$
\begin{aligned}
\frac{\mathrm{d}^{2}\left[\mathrm{~V}^{2+}\right]_{\text {cell }}}{\mathrm{d} t^{2}} & =-Q_{0}\left(\frac{1}{\mathrm{~V}_{\text {tank }}}+\frac{1}{\text { cell }}\right) \frac{\mathrm{d}\left[\mathrm{V}^{2+}\right]_{\text {cell }}}{\mathrm{d} t} \\
& \mp \frac{1}{\mathrm{~V}_{\text {cell }} F} \frac{\mathrm{d} I}{\mathrm{~d} t} \mp \frac{Q_{0}}{\mathrm{~V}_{\text {tank }} \mathrm{V}_{\text {cell }}} \frac{I}{F}
\end{aligned}
$$

Here, the concentration of the vanadium ion in the tank is governed by:

$$
\frac{\mathrm{d}\left[\mathrm{V}^{2+}\right]_{\text {tank }}}{\mathrm{d} t}=\frac{1}{V_{\text {tank }}}\left\{-\mathrm{V}_{\text {cell }} \frac{\mathrm{d}\left[\mathrm{V}^{2+}\right]_{\text {cell }}}{\mathrm{d} t} \mp \frac{I}{F}\right\}
$$

It is assumed that the concentration of vanadium ion keeps the equal amount in both positive and negative electrode as mentioned above. In addition, the concentration of hydrogen ion is also assumed to be neglected in tanks and cells. Then the following electrical relationships are held $[35,36]$ :

$$
E_{\text {no }}=E^{0}+\frac{2 R T}{F} \operatorname{Ln} \frac{\left[\mathrm{V}^{2+}\right]_{\text {cell }}}{\left[\mathrm{V}_{\max }\right]-\left[\mathrm{V}^{2+}\right]_{\text {cell }}}
$$

On the other hand, the on-load voltage is decided through the circuit relation [25]:

$$
E_{\mathrm{on}}=E_{\mathrm{no}} \mp I(r+Z)
$$

Figure 2 shows the schematic discharging circuit. The model equation is derived based in Equation (49). Here the current begins to change at the instant the switch is turned on. The current follows [37]:

$$
\frac{\mathrm{d} i}{\mathrm{~d} t}-\frac{1}{L}\left\{E-\left(r_{e s}+r_{o h m}\right) I\right\}=0
$$

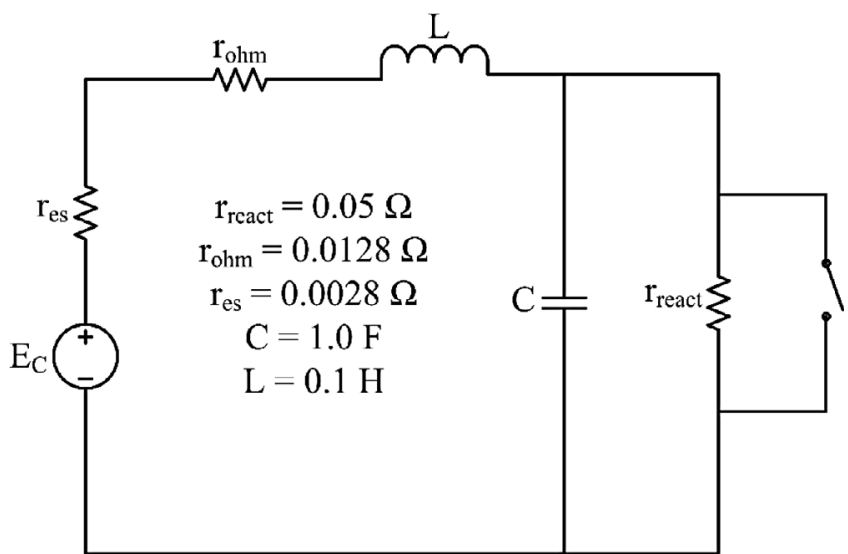

Fig. 2. Discharging circuit of the VRB.

From the above analysis, the equivalent discharging circuit of the VRB is shown in Figure 2, where $r_{o h m}$ stands for ohmic resistance, the plat double-layer capacitance $(C)$ is connected in parallel with the reaction resistance $\left(r_{\text {react }}\right)$ to stand for the half-circle of electrochemical polarization at high frequency.

Also, the equivalent series resistance $\left(r_{e s}\right)$ has two different amounts in charge and discharge conditions [37], that it has been supposed constant during both operations in this study.

Since an accurate estimation method can well prevent the over-charge/discharge of battery, SOC estimation is another key problem in management of VRB. The state of charge of a battery reflects the energy stored in the battery and its value can be measured precisely by chemical method. The state of charge of the system can be monitored by measuring the OCV using the Nernst Equations (12) and (13) as follows [36]:

$$
O C V=E_{\text {cell }}=E_{\text {cell }}^{0}+\frac{R T}{n_{V} F} \operatorname{Ln} \frac{\left[\mathrm{V}^{5+}\right]\left[\mathrm{V}^{2+}\right]\left[\mathrm{H}^{+}\right]^{2}}{\left[\mathrm{~V}^{4+}\right]\left[\mathrm{V}^{3+}\right]}
$$

where $\left[\mathrm{V}^{5+}\right]=\left[\mathrm{V}^{2+}\right]$ and $\left[\mathrm{V}^{4+}\right]=\left[\mathrm{V}^{3+}\right]$,

also $\left[\mathrm{V}^{5+}\right] \propto S O C$ and $\left[\mathrm{V}^{4+}\right] \propto 1-S O C$,

therefore, $\left[\mathrm{V}^{5+}\right]=\left[\mathrm{V}^{5+}\right]_{i}\left(\mathrm{SOC}^{*}\right)$,

and $\left[\mathrm{V}^{4+}\right]=\left[\mathrm{V}^{4+}\right]_{i}\left(1-\mathrm{SOC}^{*}\right)$.

Therefore at $25^{\circ} \mathrm{C}$,

$$
\begin{aligned}
E_{\mathrm{cell}} & =E_{\mathrm{cell}}^{0}+\frac{R T}{n_{V} F} \operatorname{Ln}\left[H^{+}\right]^{2}+\frac{R T}{n_{V} F} \operatorname{Ln} \frac{\left[\mathrm{SOC}^{*}\right]^{2}}{\left[1-\mathrm{SOC}^{*}\right]^{2}} \\
& =E_{\mathrm{cell}}^{0, *}+\frac{R T}{n_{V} F} \operatorname{Ln} \frac{\left[\mathrm{SOC}^{*}\right]^{2}}{\left[1-\mathrm{SOC}^{*}\right]^{2}}
\end{aligned}
$$

where $E_{\text {cell }}^{0, *}$ is the cell potential at $50 \%$ SOC, and SOC* the state of charge expressed as a fraction.

Standard potential $E^{0}$ is dependent with temperature and have a relationship in Equation (56) in reference [20],

$$
\frac{\partial E^{0}}{\partial t}=\frac{1}{n F}\left(\frac{\partial \Delta G}{\partial T}\right)
$$


Table 4. Standard Gibbs free enthalpy for vanadium compounds.

\begin{tabular}{ccc}
\hline Component & State & $\Delta G_{f}\left(\mathrm{~kJ} . \mathrm{mol}^{-1}\right)$ \\
\hline $\mathrm{V}^{2+}$ & $\mathrm{aq}$ & -218 \\
$\mathrm{~V}^{3+}$ & $\mathrm{aq}$ & -251.3 \\
$\mathrm{~V}^{4+}$ & $\mathrm{aq}$ & -446.4 \\
$\mathrm{~V}^{5+}$ & $\mathrm{aq}$ & -587.0 \\
$\mathrm{H}_{2} \mathrm{O}$ & $\mathrm{aq}$ & -273.2 \\
$\mathrm{H}^{+}$ & $\mathrm{aq}$ & 0 \\
\hline
\end{tabular}

where $\Delta G$ refers to the standard Gibbs free enthalpy and the values of it are listed in Table 4 .

\section{Numerical solution}

The calculated model of vanadium battery is a mathematical demonstration of electrochemical process governing the battery function.

This model contains a set of detailed differential equations along with boundary conditions which describe transmission process. It also contains equations which demonstrate the connection between transmission equations. The equations which explain the physical and electrochemical features of the utilized materials in vanadium battery, are required in modeling.

The described equations of previous parts have been solved using the COMSOL Multiphysics ${ }^{\circledR}$ (acceptable error rate $2.5 \times 10^{-6}$ ) and MATLAB softwares.

The dimensions of battery cell have been considered $85 \times 87.5 \times 4 \mathrm{~mm}$ for positive and negative carbon felts. The dimensions of $85 \times 87.5 \times 0.203 \mathrm{~mm}$ have been considered for polymer membrane.

Defined electrode, membrane and electrolyte properties in VRB modeling have been demonstrated in Tables 3,5 and 6 , respectively.

Table 7 has presented defined operational parameters in modeling VRB and their amounts based on experimental references.

\section{Results and discussion}

The results achieved by the model have been evaluated and developed as follow.

\subsection{Concentration changes}

To govern the concentration of ions the electrode reactions and flow of electrolysis solution: because of the pressured electrolysis solution by pumps the concentration change in the cell becomes small. The tanks obviously have higher concentrations than cells at charging operation. On the contrary, the concentrations in tanks are lower than in cells at discharging operation. This implies that the electrolysis solution is continuously supplied
Table 5. Considered membrane properties in VRB.

\begin{tabular}{cccc}
\hline Parameter & Value & Unit & Description \\
\hline$d_{\mathrm{m}}$ & $2.03 \times 10^{-4}$ & $\mathrm{~m}$ & Membrane thickness \\
$c_{\mathrm{f}}$ & 1990 & mol.m & Fixed charge \\
& & & site concentration \\
$z_{\mathrm{f}}$ & -1 & - & Charge of fixed site \\
$\sigma_{\mathrm{m}}$ & 10 & ${\mathrm{~S} . \mathrm{m}^{-1}}^{-3}$ & Membrane conductivity \\
\hline
\end{tabular}

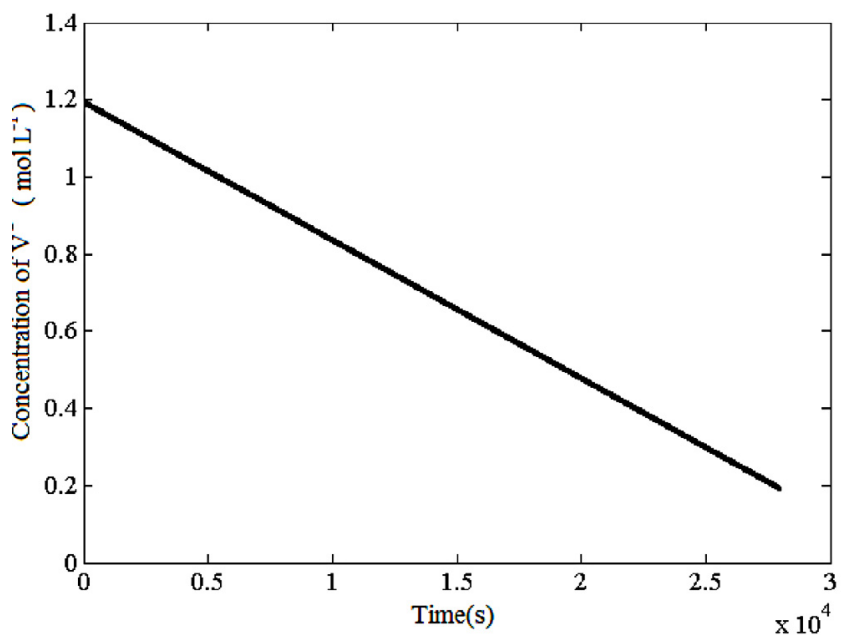

Fig. 3. Concentration change of $\mathrm{V}^{2+}$ in discharge mode.

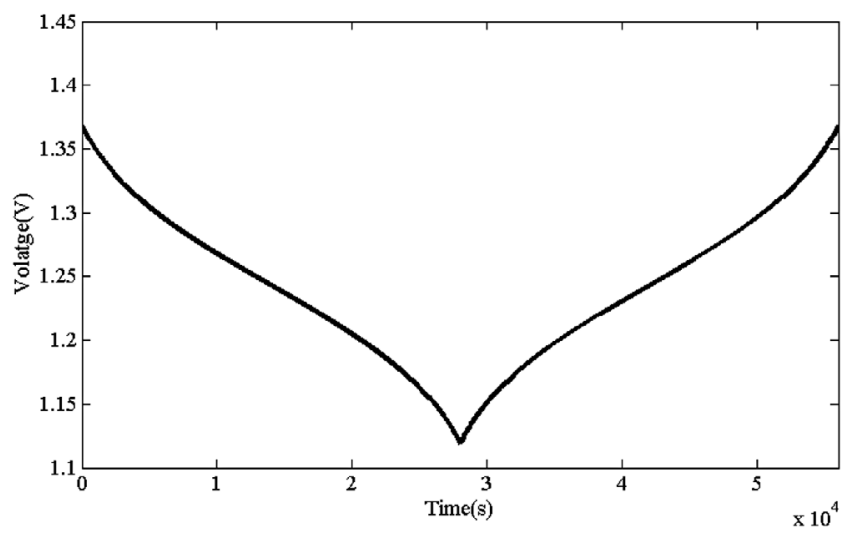

Fig. 4. Simulation result curves of output voltage in a discharge/charge cycle.

from tanks to cells. Simultaneously, the voltage increases in charging and decreases in discharging.

The changes related to $\mathrm{V}^{2+}$ concentration, have been shown in Figure 3 while continues cell discharging. It is clear that the amount of vanadium concentration decrease in tanks causes decrease in SOC battery amount. Thus concentration decrease is not accepted more than 600 mol. $\mathrm{m}^{-3}$ while discharging in VRB operation range.

\subsection{Voltage changes during charge/discharge cycle}

Changes due to electrical potential has been demonstrated in Figure 4. As it is noticed in the figure electrical 
H.A. Ozgoli and S. Elyasi: Mechanics \& Industry 17, 406 (2016)

Table 6. Considered electrolyte properties in VRB.

\begin{tabular}{cccc}
\hline Parameter & Value & Unit & Description \\
\hline$\mu_{\text {neg }}$ & 0.0025 & $\mathrm{~Pa} . \mathrm{s}$ & $\begin{array}{c}\text { Average dynamic viscosity of negative electrolyte } \\
\text { Average dynamic viscosity of positive electrolyte }\end{array}$ \\
$\mu_{\text {pos }}$ & 0.005 & $\mathrm{~Pa} . \mathrm{s}$ & $\mathrm{V}^{2+}$ initial concentration \\
$c_{\mathrm{V}_{2}}^{0}$ & 1200 & $\mathrm{~mol} \cdot \mathrm{m}^{-3}$ & $\mathrm{~V}^{3+}$ initial concentration \\
$c_{\mathrm{V}_{3}}$ & 300 & $\mathrm{~mol} \cdot \mathrm{m}^{-3}$ & $\mathrm{VO}^{2+}$ initial concentration \\
$c_{\mathrm{V}_{4}}$ & 1200 & $\mathrm{~mol} \cdot \mathrm{m}^{-3}$ & $\mathrm{VO}_{2}^{+}$initial concentration \\
$c_{\mathrm{V}_{5}}^{0}$ & 300 & $\mathrm{~mol} \cdot \mathrm{m}^{-3}$ & $\mathrm{~V}^{2+}$ diffusion coefficient \\
$D_{\mathrm{V}_{2}}$ & $2.40 \times 10^{-10}$ & $\mathrm{~m}^{2} \cdot \mathrm{s}^{-1}$ & $\mathrm{~V}^{3+}$ diffusion coefficient \\
$D_{\mathrm{V}_{3}}$ & $2.40 \times 10^{-10}$ & $\mathrm{~m}^{2} \cdot \mathrm{s}^{-1}$ & $\mathrm{VO}^{2+}$ diffusion coefficient \\
$D_{\mathrm{V}_{4}}$ & $3.90 \times 10^{-10}$ & $\mathrm{~m}^{2} \cdot \mathrm{s}^{-1}$ & $\mathrm{VO}_{2}^{+}$diffusion coefficient \\
$D_{\mathrm{V}_{5}}$ & $3.90 \times 10^{-10}$ & $\mathrm{~m}^{2} \cdot \mathrm{s}^{-1}$ & $\mathrm{H}^{+}$diffusion coefficient \\
$D_{\mathrm{H}^{+}}$ & $9.31 \times 10^{-9}$ & $\mathrm{~m}^{2} \cdot \mathrm{s}^{-1}$ & $\mathrm{SO}_{4}^{2-}$ diffusion coefficient \\
$D_{\mathrm{SO}_{4}}$ & $1.07 \times 10^{-9}$ & $\mathrm{~m}^{2} \cdot \mathrm{s}^{-1}$ & $\mathrm{HSO}_{4}^{-}$diffusion coefficient \\
$D_{\mathrm{HSO}_{4}}$ & $1.33 \times 10^{-9}$ & $\mathrm{~m}^{2} \cdot \mathrm{s}^{-1}$ &
\end{tabular}

Table 7. Considered operational parameters in VRB.

\begin{tabular}{cccc}
\hline Parameter & Value & Unit & Description \\
\hline$T$ & 293.15 & $\mathrm{~K}$ & Cell temperature \\
$Q$ & 3.6 & L.min $^{-1}$ & Volumetric flow rate \\
$v$ & 0.0127 & ${\mathrm{~m} . \mathrm{s}^{-1}}^{\text {Inlet velocity }}$ & Outlet pressure \\
$P_{\text {out }}$ & 0 & $\mathrm{~Pa}$ & Condition \\
\hline
\end{tabular}

potential is decreased whilst discharge process. The reasons are applying the introduced electrical reactions and also the electrical current production in battery cells.

This issue is also noticed about electrical potential of charge/discharge cycles. So that electrical potential shows an ascending trend while discharging and a descending trend while discharging.

According to Figure 5 the rate of electrolyte potential reduces from negative to positive side at a certain time of cell operation. This is because of electric potential generation while discharging on the negative side. The maximum rate of electrolyte potential has been calculated as $0.25 \mathrm{~V}$ on the negative side. The results of the modeling indicate that the maximum voltage of cell electrode in the beginning of discharge process has been calculated almost about $1.37 \mathrm{~V}$.

\subsection{SOC changes}

During the simulation, the cell was charged to a maximum voltage of $1.4 \mathrm{~V}$ and discharged to a minimum voltage of $1.1 \mathrm{~V}$, which is equivalent to $95 \%$ and $10 \%$ SOC, respectively.

According to the descriptions of previous sections, SOC changes have been shown in Figure 6 in an acceptable range due to generated voltage by the cell in discharge condition.

It is noticed that the SOC rate decreases gradually and the produced electrical power by the battery reduces.

It should be noted that according to the carried out studies [20] SOC changes take place in the mentioned range while charge/discharge cycles. The duration of the

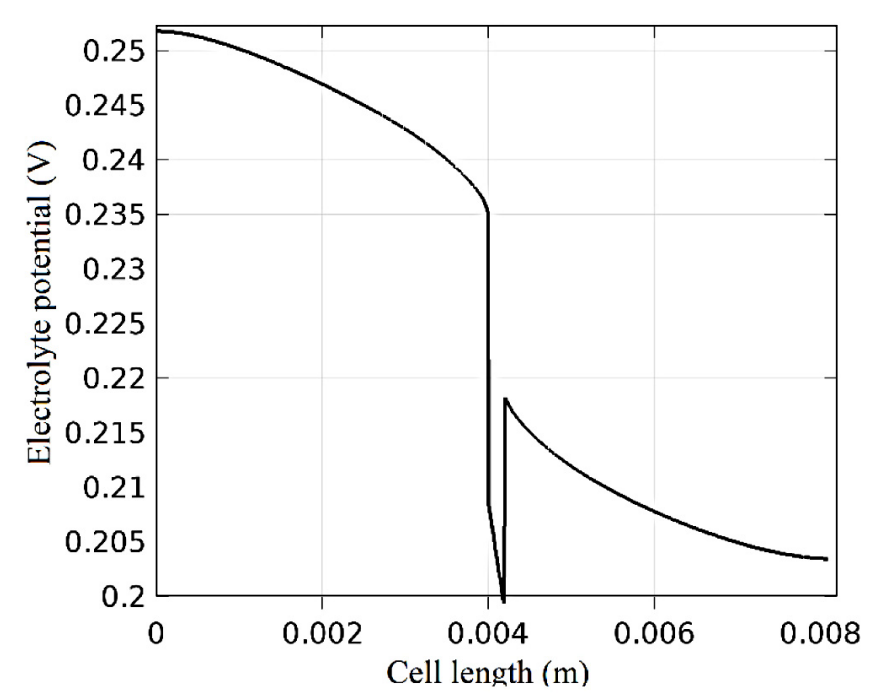

Fig. 5. Electrolyte potential change in the central cross section of the cell.

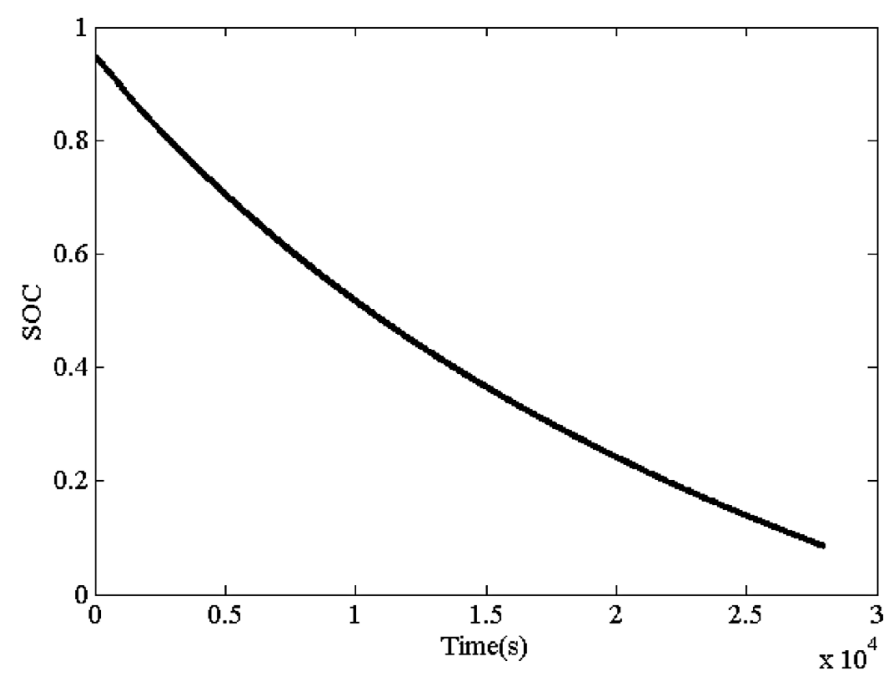

Fig. 6. SOC changes between maximum and minimum limit during discharge. 


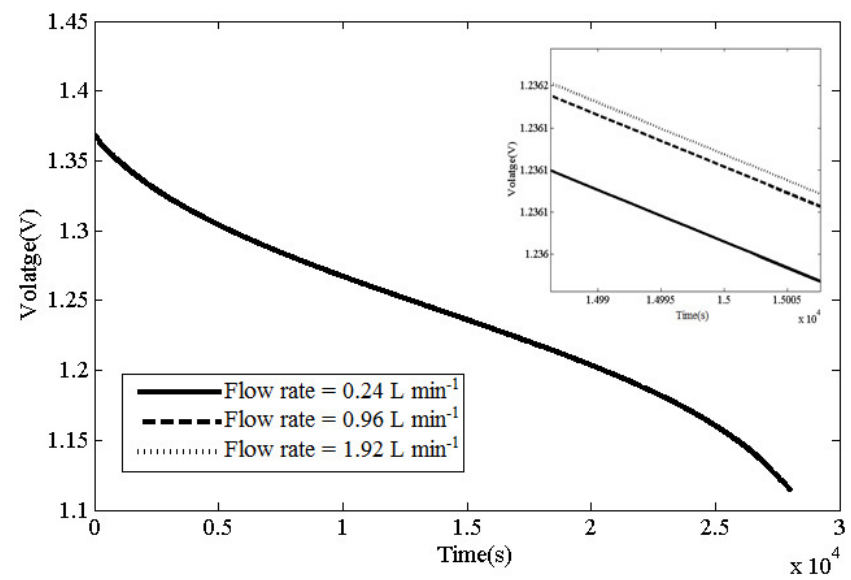

Fig. 7. Simulated discharge curves for three volumetric flow rates.

cycles is what to be decreased because of battery capacity reduction. This is because of controlling the limited voltage changes, concentration and consequently the SOC.

\section{Parametric study of system}

To carry out the parametric study various models have been created based on the fundamental one of each of which a sensitive parameter has been chosen and the effect of their changes on the model and other responses have been studied.

This parametric study is sensible and logical in each field, which means that applied changes on chosen sensitive parameters have been carried out in certain and acceptable ranges.

\subsection{Effect of flow rate}

An important control mechanism in the operation of a VRB system is the flow (pump) rate of the electrolyte. If the flow rate is too low the electrolyte can't be circulated efficiently and stagnant regions will form in the electrode. On the other hand, a flow rate that is too high runs the risk of leakage or it may cause inadequacy in performance gains for the extra power required.

High electrolyte flow rates deliver much vanadium species into cells and reduce the concentration overpotential, which contributes to a high discharge stack voltage and a low charging stack voltage according to Equations (12) and (13). The capacity of VRB is determined by the charge/discharge time at the same applied currents. It is evident that charge/discharge time is increased under high flow rates. Thus, the capacity of VRB at the same charge/discharge current is increased by high flow rate.

Due to the increase operation temperature of the cell by increasing the flow rate, voltage rise is the little amount (Fig. 7). Because as you can see in the next section, increasing the operation temperature is due to decrease the output voltage of the cell.

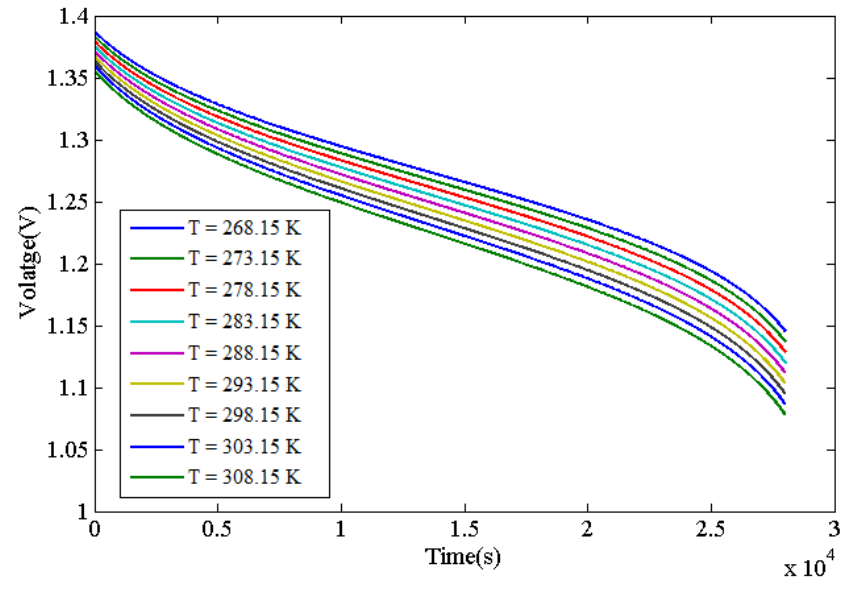

Fig. 8. Cell voltages under various surrounding temperatures.

The value of electrolyte flow rate for battery was $3.6 \mathrm{~L} \mathrm{~min}^{-1}$ in the base model. Since this parameter is one of the most effective factors from voltage output view point, calculation of charge/discharge cycles was performed based on chosen various amounts of flow rate. Achieved responses are demonstrated in Figure 7 in this study. The effect of electrolyte flow rate increase is noticed in cell electric potential increase while discharging.

\subsection{Effect of temperature}

The temperature in which the system works can be taken in to account as of the most sensitive parameters of the model.

In practice, the surrounding temperature may vary during a day and a year, the electrolyte temperature in the stack under various surrounding temperatures $(-5$ to $35{ }^{\circ} \mathrm{C}$ with constant current density) is investigated as well.

Previous studies indicate that the standard potential is temperature dependent and has a negative linear relationship between them [38].

This indicates that the system works in nonisothermal condition. The result of effect of temperature changes on electrical potential has been shown in Figure 8. As it is obvious increase in cell operation has had an undesirable effect on its output voltage therefore constructional restrictions must be considered during temperature changes range definition.

Since the activation overpotential for the electrode reactions decreases in response to improved reaction kinetics, it is expected that the cell voltage will drop as the temperature increases. Additionally, temperature alters permeability of the membrane. High temperature speeds up the diffusion rates of vanadium ions through membrane and therefore leads to a reduction of the concentrations of active vanadium ions that also releases energy from the resultant self-discharge reactions [39]. 


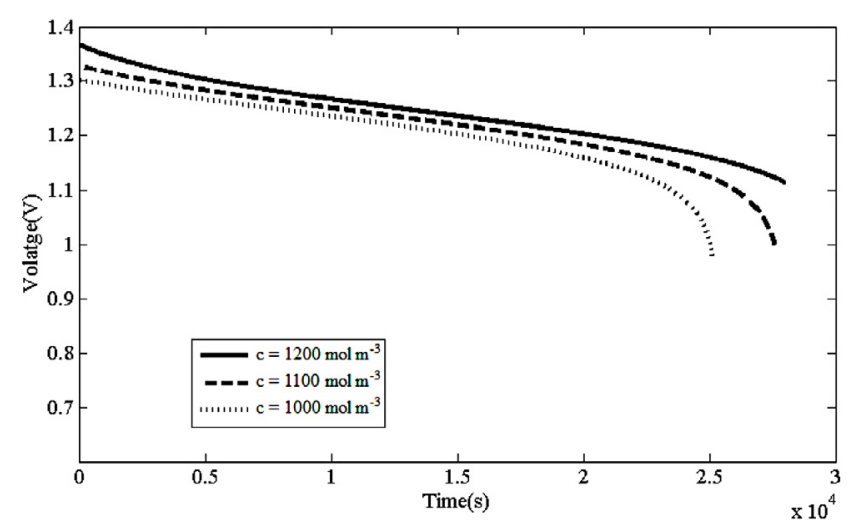

Fig. 9. Cell voltages under various initial cell concentrations of $\mathrm{V}^{2+}$.

\subsection{Effect of concentration}

According to the previous studies, the shown reaction and ohmic resistances in electrical circuit depend on battery electrolyte ion concentration [37]. As demonstrated in Figure 9, amount changes in VRB electrolyte inlets significantly affect the output voltage.

$\mathrm{V}^{5+}$ and $\mathrm{V}^{2+}$ concentration increase in electrolyte solution causes increase in generated voltage from the battery in discharge operation. It is obvious that more voltage is required to reach the desired concentration during discharge process.

\section{Conclusion}

To analyze VRB cells operation, a transient model was created as an innovation approach to predict cell operation condition, based on electrochemical equations and battery equivalent circuit concept. The results of the model indicated that changes in vanadium concentration in electrolyte solution affect the output voltage in charge and discharge condition calculated considering the primary concentration of the reactants.

The SOC amount was calculated based on reactants' changes and integration of governing equations in both sides of anode and cathode in order to control the battery operation during time. The range of SOC changes has been calculated in accordance with acceptable battery output voltage changes between 1.1 and $1.37 \mathrm{~V}$.

The sensitivity analysis of the model indicated that due to $E^{0}$ dependence on temperature, battery operation temperature increase causes voltage output decrease in discharge condition.

So that increasing $40{ }^{\circ} \mathrm{C}$ cell operation temperature, average generated voltage decreased to $0.05 \mathrm{~V}$ during discharge process. This issue contributes to SOC increase and consequently decreases battery efficient time operation.

Also effectiveness of electrolyte flow rate on battery efficient output was noticed by performing analysis in an acceptable range. The results notify generated voltage amount in VRB cell and consequently the increase in operation cycle period.

Moreover, according to presented equations about reactant's concentration changes, change was noticed in voltage amounts. It is obvious that this change, also affects directly on SOC amount of the system.

\section{References}

[1] T. Shibata, T. Kumamoto, Y. Nagaoka, K. Kawase, K. Yano, Redox Flow Batteries for the Stable Supply of Renewable Energy, SEI Technical Rev. 76 (2013) 14-22

[2] R.M. Dell, D.A.J. Rand, Energy storage a-key technology for global energy sustainability, J. Power Sources 100 (2001) $2-17$

[3] L. Jeorissen, J. Garche, C.H. Fabjan, G. Tomazic, Possible use of vanadium redox-flow batteries for energy storage in small grids and stand-alone photovoltaic systems, J. Power Sources 127 (2004) 98-104

[4] H. Ghadamian, A.A. Hamidi, H. Farzaneh, H.A. Ozgoli, Thermo-economic analysis of absorption air cooling system for pressurized solid oxide fuel cell/gas turbine cycle, J. Renew. Sust. Energy 4 (2012) 043115-1 to 043115-14

[5] Z. Yang, J. Zhang, M.C.W. Kintner-Meyer, X. Choi, D. Lu, L.P. Lemmon, J. Liu, Electrochemical energy storage for green grid, Chem. Rev. 111 (2011) 3577-3613

[6] C. Ponce de Leon, A. Frias-Ferrer, J. Gonzalez Garcia, D.A. Szanto, F. C. Walsh, Redox flow cells for energy conversion, J. Power Sources 160 (2006) 716-732

[7] G. Kear, A.A. Shah, F.C. Walsh, Development of the all-vanadium redox flow battery for energy storage: a review of technological, financial and policy aspects, Int. J. Energy Res. 36 (2011) 1105-1120

[8] M. Skyllas-Kazacos, C. Menicats, The vanadium redox battery for emergency back-up applications, Proceedings of the 19th Intelec Meeting, IEEE Communication Society, Melbourne, Australia, 1997, pp. 463-471

[9] The VRB Energy Storage System (VRB-ESS ${ }^{T M}$ ) the multiple benefits of integrating the VRB-ESS with wind energy - Case studies in MWH applications, Technical report, VRB Power Systems Inc., available in: http:// wenku. baidu.com/view/4edece768e9951e79b8927a8, 2007

[10] M.R. Mohamed, H. Ahmad, M.N. Abu Seman, Estimating the State-of-Charge of all-Vanadium Redox Flow Battery using a Divided, Open circuit Potentiometric Cell, Electronika IR Elektrotechnika 19 (2013) 37-42

[11] D.S. Aaron, Q. Liu, Z. Tang, G.M. Grim, A.B. Papandrew, A. Turhan, T.A. Zawodzinski, M.M. Mench, Dramatic Performance Gains in Vanadium Redox Flow Batteries Through Modified Cell Architecture, J. Power Sources 206 (2012) 450-453

[12] Q. Xu, T.S. Zhao, P.K. Leung, Numerical investigations of flow field designs for vanadium redox flow batteries, Appl. Energy 105 (2013) 47-56

[13] M.R. Mohamed, S.M. Sharkh, H. Ahmad, M.N. Abu Seman, F.C. Walsh, Design and development of unit cell and system for vanadium redox flow batteries (V-RFB), Int. J. Phys. Sci. 7 (2012) 1010-1024 
[14] M. Skyllas-Kazacos, R.G. Robbins, The All Vanadium Redox Battery, U.S. Patent No. 849 094, 1986

[15] V. Esfahanian, H. Mahmoodi, H. Babazadeh, M. Aghvami, R. Pasandeh, F. Torabi, G. Ahmadi, Numerical simulation of electrolyte particles trajectory to investigate battery cover design characteristics, J. Power Sources 191 (2009) 139-143

[16] A.A. Shah, M.J. Watt-Smith, F.C. Walsh, A dynamic performance model for redox-flow batteries involving soluble species, Electrochimica Acta 53 (2008) 8087-8100

[17] D. You, H. Zhang, J. Chen, A simple model for the vanadium redox battery, Electrochimica Acta 54 (2009) 68276836

[18] A. Tang, S. Ting, J. Bao, M. Skyllas-Kazacos, Thermal modelling and simulation of the all-vanadium redox flow battery, J. Power Sources 203 (2012) 165-176

[19] S. Corcuera, M. Skyllas-Kazacos, State-Of-Charge Monitoring and Electrolyte Rebalancing Methods for the Vanadium Redox Flow Battery, Eur. Chem. Bull. 1 (2012) 511-519

[20] K.W. Knehr, E. Agar, C.R. Dennison, A.R. Kalidindi, E.C. Kumbur, A Transient Vanadium Flow Battery Model Incorporating Vanadium Crossover and Water Transport through the Membrane, J. Electrochem. Soc. 159 (2012) A1446-A1459

[21] D. You, H. Zhang, C. Sun, X. Ma, Simulation of the self-discharge process in vanadium redox flow battery, J. Power Sources 196 (2011) 1578-1585

[22] M. Li, T. Hikihara, A Coupled Dynamical Model of Redox Flow Battery Based on Chemical Reaction, Fluid Flow, and Electrical Circuit, Institute of Electronics, Information and Communication Engineers, IEICE Transactions on Fundamentals of Electronics, Commun. Comput. Sci. E91-A (2008) 1741-1727

[23] P. Zhao, H. Zhang, H. Zhou, J. Chen, S. Gao, B. $\mathrm{Yi}$, Characteristics and performance of $10 \mathrm{~kW}$ class allvanadium redox-flow battery stack, J. Power Sources 162 (2006) 1416-1420

[24] M.R. Mohamed, H. Ahmad, M.N. Abu Seman, S. Razali, M.S. Najib, Electrical circuit model of a vanadium redox flow battery using extended Kalman filter, J. Power Sources 239 (2013) 284-293

[25] B. Xiong, J. Zhao, K.J. Tseng, M. Skyllas-Kazacos, T.M. Lim, Y. Zhang, Thermal hydraulic behavior and efficiency analysis of an all-vanadium redox flow battery, J. Power Sources 242 (2013) 314-324

[26] X. Binyu, J. Zhao, W. Zhongbao, Z. Chenda, State of Charge Estimation of an All-Vanadium Redox Flow Battery Based on a Thermal-Dependent Model, Power and Energy Engineering Conference (APPEEC), IEEE PES Asia-Pacific, 8-11 Dec., Kowloon, (2013) 1-6
[27] A. Tang, J. Bao, M. Skyllas-Kazacos, Dynamic modelling of the effects of ion diffusion and side reactions on the capacity loss for vanadium redox flow battery, J. Power Sources 196 (2011) 10737-10747

[28] H.A. Ozgoli, S. Elyasi, M. Mollazadeh, Hydrodynamic and electrochemical modeling of vanadium redox flow battery, Mechanics \& Industry, Accepted 22 August 2014, DOI: $10.1051 / \mathrm{meca} / 2014071$

[29] H. Al-Fetlawi, A.A. Shah, Walsh, F.C. Non-isothermal modelling of the all-vanadium redox flow battery, Electrochim. Acta 55 (2009) 78-89

[30] H. Al-Fetlawi, A.A. Shah, F.C. Walsh, Modelling the effects of oxygen evolution in the all-vanadium redox flow battery, Electrochim. Acta 55 (2010) 3192-3205

[31] M. Vynnycky, Analysis of a model for the operation of a vanadium redox battery, Energy 36 (2011) 2242-2256

[32] D. Schmal, J. Van Erkel, P.J. Van Dnin, Mass transfer at carbon fibre electrodes, J. Appl. Electrochem. 16 (1986) $422-430$

[33] M. Tomadakis, T.J. Robertson, Viscous permeability of random fiber structures: comparison of electrical and diffusional estimates with experimental and analytical results, J. Compos. Mater. 39 (2005) 163-187

[34] J. Gonzalez-Garcìa, P. Bonete, E. Exposito, V. Montiel, A. Aldaz, R. Torregrosa-Macia, Characterization of a carbon felt electrode: structural and physical properties, J. Mater. Chem. 9 (1999) 419-426

[35] E. Sum, M. Skyllas-Kazacos, A study of V(II)/V(III) redox couple for redox flow cell applications, J. Power Sources 15 (1985) 179-190

[36] T. Sukkar, M. Skyllas-Kazacos, Water transfer behaviour across cation exchange membranes in the vanadium redox battery, J. Membrane Science 222 (2003) 235-247

[37] Y. Wen, H. Zhang, P. Qian, P. Zhao, H. Zhou, B. Yi, Investigations on the Electrode Process of Concentrated $\mathrm{V}(\mathrm{IV}) / \mathrm{V}(\mathrm{V})$ Species in a Vanadium Redox Flow Battery, Acta Physico-Chimica Sinica 22 (2006) 403-408

[38] A. Heintz, C. Illenberger, Thermodynamics of vanadium redox flow batteries - electrochemical and calorimetric investigations, Berichte der Bunsengesellschaft für physikalische Chemie 102 (1998) 1401-1409

[39] A. Tang, J. Bao, M. Skyllas-Kazacos, Thermal modelling of battery configuration and self -discharge reactions in vanadium redox flow battery, J. Power Sources 216 (1992) 489-501, 2012 